\title{
Predictors of Stable Outcome in Treating Chronic Heart Failure Patients With Carvedilol
}

\author{
Wan-Jing Ho, ${ }^{1} \mathrm{MD}$, Pei-Kwei TsAY, ${ }^{2} \mathrm{PhD}$, Po-Hsien CHU, ${ }^{1} \mathrm{MD}$, \\ Chi-Jen CHAng, ${ }^{1} \mathrm{MD}$, Chi-Tai KuO, ${ }^{1} \mathrm{MD}$, and Wei-Jan ChEn, ${ }^{1} \mathrm{MD}$
}

\begin{abstract}
SUMMARY
Carverdilol has a variable outcome in treating patients with chronic heart failure. This prospective single-center study evaluated the predictors of clinical variables in determining favorable outcomes in treating chronic heart failure patients with carvedilol. The relation between clinical variables and maintenance doses of carvedilol was also determined.

Seventy chronic heart failure patients (mean age, 62.2 years, 50 males and 20 females) with a left ventricular ejection fraction $<35 \%$ and functional class II-III were enrolled in the study. The patients were clinically followed-up for at least 24 months. Patients were considered to have a favorable outcome if they had no decreases in functional class or quality-of-life score, an increase in left ventricular ejection fraction $>5 \%$, were not admitted to hospital due to worsening heart failure, and free of cardiac mortality.

Patients with favorable outcomes had a younger age $(P=0.021)$, higher baseline systolic blood pressure $(P=0.080)$, better baseline functional class $(P=0.001)$, and a higher tolerated dose of carvedilol $(P=0.026)$ than those in the unfavorable group.

In this primarily Chinese cohort of chronic heart failure patients, those with favorable outcomes were likely to be young, have a high baseline systolic blood pressure, and good baseline functional class. (Jpn Heart J 2004; 45: 823-832)
\end{abstract}

Key words: Carvedilol, Heart failure, Beta-adrenergic receptor antagonist

RECENTLY, considerable interest has developed in the use of $\beta$-blockade to treat chronic heart failure patients because $\beta$-blockade can avoid the adverse effects of sympathetic stimulation on the failing heart. ${ }^{1,2)}$ Carvedilol is a nonselective $\beta$-adrenergic receptor antagonist that also blocks $\alpha 1$-adrenergic receptors and is a potent antioxidant. ${ }^{3,4}$ Previous studies have demonstrated that carvedilol not only improves the clinical status of patients, including symptoms, left ventricular ejection fraction, and functional class, but also decreases mortality and hospitalization due to heart failure. ${ }^{5-10)}$ However, not every patient with congestive heart failure taking carvedilol has a similar outcome in clinical practice. ${ }^{5-10)}$ Since

From the ${ }^{1}$ First Cardiovascular Division, Department of Internal Medicine, Chang Gung Memorial Hospital, ${ }^{2}$ Department of Public Health \& Center of Biostatistics, College of Medicine, Chang Gung University, Tao-Yuan, Taiwan.

Address for correspondence: Wei-Jan Chen, MD, First Cardiovascular Division, Department of Internal Medicine, Chang

Gung Memorial Hospital, No. 5, Fu-Shin Road, Kwei-Shan, Tao-Yuan, Taiwan 333.

Received for publication December 4, 2003.

Revised and accepted March 19, 2004. 
most congestive heart failure studies have been carried out in Caucasian populations, whether clinical variables associated with the clinical response differ in other ethnic groups should be established. Furthermore, because of the relatively small build of Chinese patients, it is also necessary to determine whether such patients can tolerate dosages of carvedilol as high as those suggested for Caucasian subjects.

This prospective single-center study examined clinical outcomes over a two-year follow-up period, and the association of favorable outcomes with clinical variables, among patients with chronic heart failure receiving carvedilol. The relation between clinical variables and maintenance doses of carvedilol in treating heart failure patients was also determined.

\section{Methods}

Patients: This prospective study was conducted in 70 consecutive patients (mean age, $62.2 \pm 12.3$ years, 50 males, body mass index, $24.2 \pm 4.3 \mathrm{~kg} / \mathrm{m}^{2}$ ) with congestive heart failure. All patients had an ejection fraction of less than $35 \%$ (mean $26.6 \pm 6.4 \%$ ) and were current New York Heart Association functional class II or III, or previous class II-IV. All of the patients had chronic heart failure history for at least one year. The ischemic and nonischemic nature of the cardiomyopathy was determined by coronary angiography. Chronic heart failure medications such as digitalis, angiotensin-converting enzyme inhibitors, angiotensin II receptor blockers, nitrates, and diuretics were maintained during the study period. Pharmacologic treatment was considered optimal and left unchanged for at least three months. The study procedure followed previously published designs used in four concurrent trials assessing the effects of carvedilol in heart failure. ${ }^{5)}$ Briefly, patients should be able to tolerate a carvedilol dose of at least $6.25 \mathrm{mg}$ twice daily. The carvedilol starting dose was always $3.125 \mathrm{mg}$ twice daily for 1 to 2 weeks, progressing to $6.25 \mathrm{mg}$ twice daily for a further week. There was a 2 to 4 week dose titration period with weekly assessment, with the aim being to increase the dose of carvedilol to a maximum of $25 \mathrm{mg}$ twice daily or alternatively to the highest dose tolerable. Maintenance treatment then continued with carvedilol 6.25-25 mg twice daily.

Clinical follow-up: All patients were followed for 24 months. Clinical and echocardiographic data were obtained by independent observers, and were collected before carvedilol treatment, and then at 6-, 12-, and 24-month follow-up. Patients were assessed for heart failure symptoms (functional class). All echocardiographic studies were performed by the same physician. Finally, left ventricular ejection fraction was assessed by radionuclide ventriculography. 
Definition of favorable outcome: To be considered to have a favorable outcome, patients had to fulfill all of the following criteria, ${ }^{8)}$ namely: (1) no change in functional status as assessed by the New York Heart Association classification (no decrease in functional class or quality-of-life score); (2) increase in left ventricular ejection fraction exceeding 5\% compared to pretreatment; (3) not admitted to hospital due to worsening heart failure; and (4) free of cardiac mortality.

Statistical analysis: Unless otherwise specified, data are presented as the mean \pm SD or frequency percentages. Student's $t$ test and the Chi-square (or Fisher's exact test for small sample sizes) test were used to compare differences between continuous variables and proportions, respectively. Moreover, univariate and multivariate stepwise logistic regression models were used to identify individual and joint predictors of a favorable outcome and also the maintenance doses of carvedilol. The threshold of significance was set at 0.05 .

\section{RESUlts}

Predictors of favorable outcome: Carvedilol elicited a favorable outcome in 43 patients (61\%) and an unfavorable outcome in 27 (39\%). Table I lists the clinical variables of patients with favorable and unfavorable outcomes. The two groups did not differ significantly in terms of gender, height, heart rate, left ventricular ejection fraction, mitral regurgitation, left atrium size, atrial fibrillation, left bundle branch block, cause of heart failure, concomitance with diabetes mellitus, and baseline medications.

Patients with favorable outcomes had a larger body mass index, higher blood pressure, better baseline functional class, smaller heart size as assessed by left ventricular end-diastolic diameter, and a higher maintenance dose of carvedilol (Table I). Moreover, patients with nephropathy and/or diabetic mellitus tended to have unfavorable outcomes.

In determining the influences on the maintenance dose of carvedilol, this study found that patients with a large body mass index and good functional class could tolerate a high maintenance dose of carvedilol (Table II). Notably, patients who could tolerate a high dose of carvedilol might have high systolic blood pressure.

Multivariate analysis of clinical variables revealed that independent predictors of a favorable outcome were a young age (odds ratio [OR] per year 1.093; $P$ $=0.021$ ) and a good baseline functional class (OR 58.946; $P=0.001)$. From the stepwise logistic regression, besides young age and good functional class, the favorable outcome group also had a higher dose of carvedilol $(P=0.026)$ (OR 14.633; $P=0.007$ in $6.25 \mathrm{mg}$ versus $25 \mathrm{mg}$, but $\mathrm{OR} 4.960 ; P=0.071$ in $12.5 \mathrm{mg}$ versus $25 \mathrm{mg}$ ). Notably, the favorable outcome group also exhibited a mild ten- 
Table I. Clinical Characteristics of Patients With Chronic Heart Failure Taking Carvedilol According to Favorable or Unfavorable Outcome

\begin{tabular}{|c|c|c|c|}
\hline & $\begin{array}{l}\text { Favorable } \\
(n=43)\end{array}$ & $\begin{array}{l}\text { Unfavorable } \\
\quad(n=27)\end{array}$ & $P$-value \\
\hline Sex (male) & $74.4 \%$ & $66.7 \%$ & 0.669 \\
\hline Age (years) & $60.5 \pm 12.9$ & $65.0 \pm 11.0$ & 0.149 \\
\hline Body height (cm) & $159.9 \pm 7.9$ & $156.9 \pm 7.5$ & 0.126 \\
\hline Body weight (kg) & $64.3 \pm 16.7$ & $56.7 \pm 9.7$ & 0.035 \\
\hline Body surface area $\left(\mathrm{m}^{2}\right)$ & $1.66 \pm 0.22$ & $1.55 \pm 0.15$ & 0.035 \\
\hline Body mass index $\left(\mathrm{kg} / \mathrm{m}^{2}\right)$ & $25.0 \pm 4.9$ & $22.9 \pm 2.8$ & 0.052 \\
\hline Systolic pressure (mmHg) & $132 \pm 21$ & $119 \pm 22$ & 0.016 \\
\hline Diastolic pressure $(\mathrm{mmHg})$ & $78 \pm 11$ & $71 \pm 13$ & 0.037 \\
\hline Heart rate (beats/min) & $79 \pm 11$ & $86 \pm 17$ & 0.106 \\
\hline Functional class & & & $<0.001$ \\
\hline II & $95.3 \%$ & $48.1 \%$ & \\
\hline III & $4.7 \%$ & $51.9 \%$ & \\
\hline LVEDD (mm) & $59.0 \pm 7.1$ & $62.7 \pm 8.6$ & 0.057 \\
\hline LVESD (mm) & $49.1 \pm 7.9$ & $52.4 \pm 9.3$ & 0.119 \\
\hline $\operatorname{LVEF}(\%)$ & $26.8 \pm 6.2$ & $26.4 \pm 6.7$ & 0.807 \\
\hline Mitral regurgitation & & & 0.392 \\
\hline mild & $55.8 \%$ & $44.5 \%$ & \\
\hline moderate & $34.9 \%$ & $37.0 \%$ & \\
\hline severe & $7.0 \%$ & $18.5 \%$ & \\
\hline LA size $(\geq 40 \mathrm{~mm})$ & $44.2 \%$ & $27.9 \%$ & 1.000 \\
\hline \multicolumn{4}{|l|}{ ECG } \\
\hline $\mathrm{AF}$ & $27.9 \%$ & $18.5 \%$ & 0.143 \\
\hline LBBB & $25.6 \%$ & $18.5 \%$ & 0.210 \\
\hline Maintenance dose & & & $<0.001$ \\
\hline $6.25 \mathrm{mg}$ & $9.3 \%$ & $51.9 \%$ & \\
\hline $12.5 \mathrm{mg}$ & $32.6 \%$ & $22.2 \%$ & \\
\hline $25 \mathrm{mg}$ & $55.8 \%$ & $25.9 \%$ & \\
\hline $50 \mathrm{mg}$ & $2.3 \%$ & $0.0 \%$ & \\
\hline \multicolumn{4}{|l|}{ Concomitant disease } \\
\hline ischemic heart disease & $30.2 \%$ & $25.9 \%$ & 0.907 \\
\hline nephropathy & $7.0 \%$ & $25.9 \%$ & 0.038 \\
\hline $\mathrm{DM}$ & $25.6 \%$ & $37.0 \%$ & 0.453 \\
\hline DM+nephropathy & $4.7 \%$ & $25.9 \%$ & 0.023 \\
\hline Sudden death & $2.3 \%$ & $25.9 \%$ & 0.004 \\
\hline \multicolumn{4}{|l|}{ Medications } \\
\hline ACE-I/ARB & $100.0 \%$ & $92.6 \%$ & 0.145 \\
\hline digitalis & $41.9 \%$ & $48.1 \%$ & 0.788 \\
\hline nitrate & $74.5 \%$ & $85.2 \%$ & 0.682 \\
\hline diuretics & $79.1 \%$ & $92.6 \%$ & 0.240 \\
\hline Mortality & $(1 / 43) 2.3 \% *$ & $(6 / 27) 22.2 \% \dagger$ & 0.009 \\
\hline
\end{tabular}

ACE-I = angiotensin-converting enzyme inhibitors; AF = atrial fibrillation; $\mathrm{ARB}=$ angiotensin II receptor blockers; $\mathrm{DM}=$ diabetes mellitus; $\mathrm{LA}=$ left atrium; LBBB = left bundle branch block; LVEDD = left ventricular end-diastolic diameter; $\mathrm{LVEF}=$ left ventricular ejection fraction; LVESD = left ventricular end-systolic diameter.

*The only death was caused by cerebral hemorrhage.

$\dagger$ Two patients died of worsening heart failure and four patients died suddenly. 
Table II. Clinical Characteristics of Patients in Chronic Heart Failure According to Different Maintenance Dose Achieved*

\begin{tabular}{|c|c|c|c|c|}
\hline & $\begin{array}{l}6.25 \mathrm{mg} \\
(n=18)\end{array}$ & $\begin{array}{l}12.5 \mathrm{mg} \\
(n=20)\end{array}$ & $\begin{array}{c}25 \mathrm{mg} \\
(n=31)\end{array}$ & $P$-value \\
\hline Sex (male) & $66.7 \%$ & $60.0 \%$ & $80.6 \%$ & 0.249 \\
\hline Age (years) & $61.4 \pm 10.6$ & $61.8 \pm 13.3$ & $62.8 \pm 13.1$ & 0.923 \\
\hline Body height $(\mathrm{cm})$ & $157.4 \pm 6.5$ & $158.2 \pm 9.3$ & $159.7 \pm 7.7$ & 0.591 \\
\hline Body weight (kg) & $57.8 \pm 11.8$ & $56.6 \pm 10.3$ & $66.8 \pm 17.4$ & 0.024 \\
\hline Body surface area $\left(\mathrm{m}^{2}\right)$ & $1.57 \pm 0.17$ & $1.56 \pm 0.16$ & $1.69 \pm 0.23$ & 0.045 \\
\hline Body mass index $\left(\mathrm{kg} / \mathrm{m}^{2}\right)$ & $23.2 \pm 3.5$ & $22.6 \pm 3.6$ & $25.9 \pm 4.6$ & 0.011 \\
\hline Systolic pressure $(\mathrm{mmHg})$ & $117 \pm 24$ & $120 \pm 22$ & $138 \pm 17$ & 0.001 \\
\hline Diastolic pressure $(\mathrm{mmHg})$ & $73 \pm 12$ & $73 \pm 12$ & $78 \pm 13$ & 0.230 \\
\hline Heart rate (beat/min) & $83 \pm 18$ & $79 \pm 17$ & $83 \pm 18$ & 0.61 \\
\hline Functional class & & & & $<0.001$ \\
\hline II & $44.4 \%$ & $95.0 \%$ & $87.1 \%$ & \\
\hline III & $55.6 \%$ & $5.0 \%$ & $12.9 \%$ & \\
\hline LVEDD (mm) & $62.7 \pm 7.3$ & $57.5 \pm 7.2$ & $60.9 \pm 8.4$ & 0.114 \\
\hline $\operatorname{LVESD}(\mathrm{mm})$ & $52.6 \pm 7.6$ & $48.0 \pm 8.7$ & $50.5 \pm 9.1$ & 0.261 \\
\hline $\operatorname{LVEF}(\%)$ & $24.0 \pm 5.8$ & $27.3 \pm 5.4$ & $27.6 \pm 7.0$ & 0.133 \\
\hline Mitral regurgitation & & & & 0.940 \\
\hline mild & $55.6 \%$ & $55.0 \%$ & $45.2 \%$ & \\
\hline moderate & $33.3 \%$ & $35.0 \%$ & $38.7 \%$ & \\
\hline severe & $11.1 \%$ & $10.0 \%$ & $12.9 \%$ & \\
\hline LA size $(\geq 40 \mathrm{~mm})$ & $38.9 \%$ & $45.0 \%$ & $47.4 \%$ & 0.718 \\
\hline \multicolumn{5}{|l|}{ ECG } \\
\hline $\mathrm{AF}$ & $22.2 \%$ & $30.0 \%$ & $22.6 \%$ & 0.824 \\
\hline LBBB & $22.2 \%$ & $25.0 \%$ & $22.6 \%$ & 0.875 \\
\hline \multicolumn{5}{|l|}{ Concomitant disease } \\
\hline ischemic heart disease & $44.4 \%$ & $15.0 \%$ & $25.8 \%$ & 0.122 \\
\hline nephropathy & $22.2 \%$ & $10.0 \%$ & $12.9 \%$ & 0.533 \\
\hline $\mathrm{DM}$ & $27.8 \%$ & $30.0 \%$ & $32.3 \%$ & 0.946 \\
\hline DM+nephropathy & $16.7 \%$ & $10.0 \%$ & $12.9 \%$ & 0.830 \\
\hline sudden death & $22.2 \%$ & $5.0 \%$ & $9.7 \%$ & 0.230 \\
\hline \multicolumn{5}{|l|}{ Medications } \\
\hline ACE-I/ARB & $94.4 \%$ & $95.0 \%$ & $100.0 \%$ & 0.429 \\
\hline digitalis & $44.4 \%$ & $55.0 \%$ & $38.7 \%$ & 0.520 \\
\hline nitrate & $88.9 \%$ & $70.0 \%$ & $87.1 \%$ & 0.208 \\
\hline diuretics & $83.3 \%$ & $100.0 \%$ & $83.9 \%$ & 0.188 \\
\hline Outcome & & & & $<0.001$ \\
\hline favorable & $22.2 \%$ & $70.0 \%$ & $77.4 \%$ & \\
\hline unfavorable & $77.8 \%$ & $30.0 \%$ & $22.6 \%$ & \\
\hline
\end{tabular}

*One patient with body weight $>80 \mathrm{~kg}$ who received carvedilol $50 \mathrm{mg}$ twice daily is not included.

ACE-I = angiotensin-converting enzyme inhibitors; AF = atrial fibrillation; $\mathrm{ARB}=$ angiotensin II receptor blocker; DM = diabetes mellitus; $\mathrm{LA}=$ left atrium; $\mathrm{LBBB}=$ left bundle branch block; LVEDD = left ventricular end-diastolic diameter; LVEF=left ventricular ejection fraction; LVESD = left ventricular end-systolic diameter.

dency towards higher systolic blood pressure (OR 0.963; $P=0.080$ ) than the unfavorable group. 
Heart rate, blood pressure, and left ventricular ejection fraction responses: Table III shows the time-related changes in heart rate, blood pressure, and left ventricular ejection fraction among patients receiving different maintenance doses of carvedilol. The heart rate decreased in all patients taking carvedilol. The systolic and diastolic blood pressures measured in the sitting position were reduced in the $6.25 \mathrm{mg}$ and $25 \mathrm{mg}$ groups, but elevated in the $12.5 \mathrm{mg}$ group. The left ventricular ejection fraction increased in all three groups.

Left ventricular function among favorable and unfavorable outcome groups: The Figure shows the time-related changes in left ventricular ejection fraction

Table III. Differences $(\Delta)$ in Heart Rates, Blood Pressures (BP), and Left Ventricular Ejection Fractions (LVEF) (mean \pm SD) From Baseline According to Different Maintenance Doses Achieved

\begin{tabular}{lccc}
\hline & $6.25 \mathrm{mg}$ & $12.5 \mathrm{mg}$ & $25 \mathrm{mg}$ \\
\hline$\Delta$ Heart rate (beat/min) & & & \\
6 months & $-9 \pm 12$ & $-2 \pm 13$ & $-18 \pm 21$ \\
12 months & $-7 \pm 12$ & $3 \pm 15$ & $-17 \pm 14$ \\
24 months & $-9 \pm 8$ & $-7 \pm 7$ & $-15 \pm 16$ \\
$\Delta$ Systolic BP (mmHg) & & & \\
6 months & $-10 \pm 20$ & $5 \pm 19$ & $-5 \pm 21$ \\
12 months & $-5 \pm 16$ & $9 \pm 18$ & $4 \pm 15$ \\
24 months & $-10 \pm 11$ & $10 \pm 32$ & $-4 \pm 14$ \\
$\Delta$ Diastolic BP (mmHg) & & & \\
6 months & $-8 \pm 10$ & $1 \pm 11$ & $-9 \pm 12$ \\
12 months & $-3 \pm 15$ & $6 \pm 15$ & $-3 \pm 12$ \\
24 months & $-1 \pm 6$ & $6 \pm 14$ & $-6 \pm 9$ \\
$\Delta$ LVEF (\%) & & & \\
6 months & $7.5 \pm 8.0$ & $9.5 \pm 8.0$ & $12.0 \pm 8.0$ \\
12 months & $3.5 \pm 9.2$ & $12.8 \pm 6.3$ & $14.8 \pm 11.4$ \\
\hline
\end{tabular}

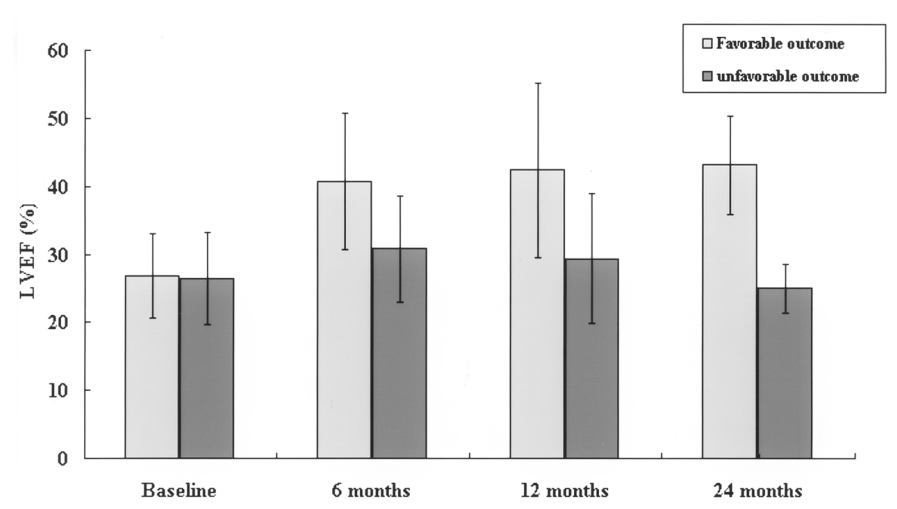

Figure. Left ventricular ejection fraction in the favorable and unfavorable outcome groups during 24 months of follow-up. Values at baseline, 6,12 , and 24 months are the mean \pm SE. 
(LVEF). LVEF increased from $26.8( \pm 6.2) \%$ at baseline to $40.7( \pm 10.1) \%, 42.4$ $( \pm 12.8) \%$, and $43.2( \pm 7.2) \%$ at 6,12 , and 24 months, respectively, in the favorable outcome group. The unfavorable outcome patients showed either little change or none at all. The two groups differed significantly $(P<0.001)$.

\section{DISCUSSION}

This study assessed the predictors of a favorable outcome from carvedilol treatment in patients with chronic heart failure. Clinical variables associated with a favorable outcome were age, body mass index, baseline blood pressure, and heart size. The findings of this study conflict with previous studies indicating that the effect of carvedilol was not influenced by age, body and heart size, or baseline blood pressure. ${ }^{5-10)}$ The disparity in these results may result from differences in study designs and population. Notably, the definition of a favorable outcome in this study is a synthesized outcome measured in patients who happen to take carvedilol. This definition did not really represent the effectiveness of carvedilol in treating heart failure patients.

Although carvedilol has been found beneficial in all spectrums ranging from mild to severe heart failure, ${ }^{5-7,10)}$ this study demonstrated that baseline functional class is one of the independent determinants of a favorable outcome in treating heart failure patients with carvedilol. This study did not enrol patients with mild or severe heart failure. Therefore, whether the results obtained from this study apply to all heart failure patients remains to be determined.

Another important determinant of clinical outcome was the maintenance dose that the patients could tolerate. Data on this variable were consistent with previous studies demonstrating that carvedilol produced a dose-related improvement of left ventricular function and survival in patients with heart failure. ${ }^{5-10)}$

This study also found that body mass index and baseline functional class were independent influences on the maintenance dose of carvedilol. Despite the relatively smaller body size in the present sample of Chinese patients compared with patients in previous studies, ${ }^{5-10)}$ the maintenance dose of carvedilol should be as high as possible for heart failure patients.

This study found that patients with nephropathy and/or diabetic mellitus were slightly nonresponsive, despite the case numbers being small. The possible cause of the failed response to carvedilol was fluid retention, which may prevent patients from improving the functional class and left ventricular ejection fraction during the late treatment period. This study thus suggested that carvedilol use should be reconsidered in the treatment of heart failure patients with nephropathy and/or diabetic mellitus. However, a recent publication by Cice, et al has showed that tremendous benefits can be achieved in nephropathy patients on dialysis with 
end-stage renal function. ${ }^{11)}$ Additionally, a recent meta-analysis of patients with diabetes and heart failure demonstrated decreased mortality following $\beta$-blocker treatment. ${ }^{12)}$ A limitation of the present study is that the mechanism of this disparity has not been clarified.

Patients with heart failure have a high incidence of ventricular arrhythmias. ${ }^{13)}$ Ventricular arrhythmias are important in clinical practice because they are a potential cause of sudden death. Carvedilol has been shown to be able to reduce the incidence of complex ventricular arrhythmias in treating heart failure patients, and thus can prevent arrhythmic death. ${ }^{14)}$ However, this study found no beneficial effect from treating eight heart failure patients who died suddenly (four patients died of recurrent sudden death). Therefore, this study suggested that other strategies, such as an automatic implantable cardioverter defibrillator, should be considered to prevent the recurrence of arrhythmic death rather than depending solely on the antiarrhythmic effects of carvedilol.

Left bundle branch block is commonly associated with ventricular dysfunction. ${ }^{15,16)}$ Intraventricular conduction delay, as manifested in left bundle branch block patients, is responsible for asynchronized left ventricular contraction owing to alteration in the sequence of left ventricular depolarization. Left bundle branch block is also associated with increased mortality among patients with congestive heart failure. ${ }^{17,18)}$ This study did not find an inverse relation between concomitant left bundle branch block and the clinical responses of carvedilol. Instead, the results demonstrated that carvedilol could convert left bundle branch block to narrow QRS complexes in certain patients with heart failure (five out of 16 patients with left bundle branch block, data not shown). Therefore, carvedilol is not contraindicated in patients with heart failure and left bundle branch block, despite possible disturbances in the conduction system.

A recent publication by Nakajima, et al has showed that carvedilol may reduce blood pressure due to its calcium channel blocking action and $\alpha$-blocking effects in smooth muscle cells. ${ }^{19)}$ In our study, we observed a reduction in blood pressure in both patient groups with carvedilol $6.25 \mathrm{mg}$ and $25 \mathrm{mg}$, but not in the $12.5 \mathrm{mg}$ group. This may be due to different etiologies and left ventricular reserves.

One of the important predictors of a prognosis in patients with chronic heart failure is the degree of left ventricular dysfunction. This study showed significant improvement in left ventricular ejection fraction in the favorable group. This finding is compatible with previous studies showing that ejection fraction can be improved by $\beta$-blocker treatment in chronic heart failure..$^{20,21)}$ The possible mechanism of this difference between favorable and unfavorable outcomes may be a different degree of improvement of left ventricular function by the carvedilol used in different left ventricular reserves. 
Study limitations: Since this study is not a placebo-controlled randomized clinical trial, it cannot determine many treatment responses. Indeed, the use of carvedilol is just one of the influences on the natural history of chronic heart failure. Additionally, this study did not enroll a large number of patients, making it impossible to evaluate the outcome of heart failure in different etiologies. The main finding from this Chinese cohort, as compared with previous essentially Caucasian cohorts, is that there are differences in the predictors of favorable outcomes.

Conclusions: This prospective study confirmed the beneficial effects of carvedilol in treating heart failure patients. Patients with a favorable outcome were likely to be young, have high baseline systolic blood pressure, and a good baseline functional class.

\section{REFERENCES}

1. Packer M. Beta-adrenergic blockade in chronic heart failure: principles, progress, and practice. Prog Cardiovasc Dis 1998; 41: 39-52.

2. $\quad$ Bristow MR. $\beta$-adrenergic receptor blockade in chronic heart failure. Circulation 2000; 101: 558-69.

3. Ruffolo RR Jr, Gellai M, Hieble JP, Willette RN, Nichols AJ. The pharmacology of carvedilol. Eur J Clin Pharmacol 1990; 38: S82-8.

4. Yue TL, Cheng HY, Lysko PG, et al. Carvedilol, a new vasodilator and beta adrenoceptor antagonist, is an antioxidant and free radical scavenger. J Pharmacol Exp Ther 1992; 263: 92-8.

5. Packer M, Bristow MR, Cohn JN, et al. The effect of carvedilol on morbidity and mortality in patients with chronic heart failure. N Engl J Med 1996; 334: 1349-55.

6. Australia-New Zealand Heart Failure Research Collaborative Group. Randomised, placebo-controlled trial of carvedilol in patients with congestive heart failure due to ischemic heart disease. Lancet 1997; 349: 375-80.

7. Australia-New Zealand Heart Failure Research Collaborative Group. Effects of carvedilol, a vasodilator- $\beta$ blocker, in patients with congestive heart failure due to ischemic heart disease. Circulation 1995; 92: 212-8.

8. Lechat P, Packer M, Chalon S, Cucherat M, Arab T, Boissel JP. Clinical effects of $\beta$-adrenergic blockade in chronic heart failure: a meta-analysis of double-blind, placebo-controlled, randomized trials. Circulation 1998; 98: 1184-91.

9. Heidenreich PA, Lee TT, Massie BM. Effect of beta-blockade on mortality in patients with heart failure: a meta-analysis of randomized clinical trials. J Am Coll Cardiol 1997; 30: 27-34.

10. Packer M, Fowler MB, Roecker EB, et al. Effect of carvedilol on morbidity of patients with severe chronic heart failure: results of the carvediol prospective randomized cumulative survival (COPER NICUS) study. Circulation 2002; 106: 2194-9.

11. Cice G, Ferrara L, D'Andrea A, et al. Carvedilol increases two-year survival in dialysis patients with dilated cardiomyopathy. J Am Coll Cardiol 2003; 41: 1438-44.

12. Shekelle PG, Rich MW, Morton SC, et al. Efficacy of angiotensin-converting enzyme inhibitors and betablockers in the management of left ventricular systolic dysfunction according to race, gender, and diabetic status: a meta-analysis of major clinical trials. J Am Coll Cardiol 2003; 41: 1529-38.

13. Podrid PJ, Fogel RI, Fuchs TT. Ventricular arrhythmia in congestive heart failure. Am J Cardiol 1992; 69: 82G96.

14. Cice G, Tagliamonte E, Ferrara L, Lacono A. Efficacy of carvedilol on complex ventricular arrhythmias in dilated cardiomyopathy: double-blind, randomized, placebo-controlled study. Eur Heart J 2000; 21: 1259-64. 
15. Schneider JF, Thomas HE Jr, Sorlie P, Kreger BE, McNamara PM, Kannel WB. Comparative features of newly acquired left and right bundle branch block in the general population: the Framingham study. Am J Cardiol 1981; 47: 931-40.

16. Hamby RI, Weissman RH, Prakash MN, Hoffman I. Left bundle branch block: a predictor of poor left ventricular function in coronary artery disease. Am Heart J 1983; 106: 471-7.

17. Baldasseroni S, Opasich C, Gorini M, et al. Left bundle-branch block is associated with increased 1-year sudden and total mortality rate in 5517 outpatients with congestive heart failure: a report from the Italian network on congestive heart failure. Am Heart J 2002; 143: 398-405.

18. Iuliano S, Fisher SG, Karasik PE, Fletcher RD, Singh SN. QRS duration and mortality in patients with congestive heart failure. Am Heart J 2002; 143: 1085-91.

19. Nakajima T, Ma J, lida H, et al. Inhibitory effects of carvedilol on calcium channels in vascular smooth muscle cells. Jpn Heart J 2003; 44: 963-78.

20. Van Campen LC, Visser FC, Visser CA. Ejection fraction improvement by $\beta$-blocker treatment in patients with heart failure: an analysis of studies published in the literature. J Cardiovasc Pharmacol 1998; 32(1 suppl): S315.

21. Packer M, Antonopoulos GV, Berlin JA, Chittams J, Konstam MA, Udelson JE. Comparative effects of carvedilol and metoprolol on left ventricular ejection fraction in heart failure: results of a meta-analysis. Am Heart J 2001; 141: 899-907. 